\title{
METODOLOGIA ALTERNATIVA DE ENSINO-APRENDIZAGEM PROMOVENDO A ALFABETIZAÇÃO ESTATÍSTICA AOS ALUNOS DO ENSINO FUNDAMENTAL
}

Amanda Liz Pacífico Manfrim Perticarrari ${ }^{1}$, Andreia da Silva Meyer ${ }^{1}$, Nelson José Peruzzi ${ }^{1}$, Aline Maria Pacífico Manfrim ${ }^{2}$, Glauco de Souza Rolim ${ }^{1}$, Danísio Prado Munari ${ }^{1}$, Antonio Sergio Ferraudo ${ }^{1}$

${ }^{1}$ Universidade Estadual Paulista, FCAV, Depto. Ciências Exatas, Jaboticabal, São Paulo, Brasil

${ }^{2}$ Instituto Federal de São Paulo, Araraquara, São Paulo, Brasil amanda@fcav.unesp.br

As informações estatísticas sempre estiveram presentes na vida dos cidadãos e assim como muitas pessoas confiam e utilizam para nortear suas decisões, outras desconfiam e/ou atacam sua verossimilhança (CAZORLA, 2008). Os Parâmetros Curriculares Nacionais sugerem o incentivo da leitura e da interpretação de gráficos, de tabelas e de medidas publicadas pelos diversos meios de comunicação, para que o aluno saiba posicionar-se de forma crítica diante dessas informações e fornecer-lhes ferramentas para arguir e findar informações enviesadas (LOPES et al, 2010). Dessa forma, o presente trabalho visa promover uma alfabetização estatística aos alunos do Ensino Fundamental (EF), desenvolvendo uma metodologia alternativa de ensino-aprendizagem em probabilidade e estatística, cuja teoria e aplicação são abordadas através do desenvolvimento de material didático desenvolvido especificamente a partir conhecimentos prévios e práticas do cotidiano do aluno de EF.

Para o desenvolvimento do material didático foi aplicado um questionário fechado a 200 alunos do EF, baseado em uma escala que permite respostas com níveis variados, de forma que os dados foram padronizados em uma mesma escala. O mesmo foi estruturado sobre questões cotidiano desse público possibilitando identificar situações-problema a serem exploradas. Estes foram tabulados e uma análise descritiva resumiu as informações das respostas obtidas por meio do questionário. Posteriormente, foi possível a elaboração de situações-problemas envolvendo conteúdos de estatística.

A partir do questionário aplicado, esta sendo possível coletar e organizar os dados para o desenvolvimento de uma apostila contendo atividades do cotidiano dos alunos do EF visando uma metodologia alternativa para o desenvolvimento da educação estatística nas séries iniciais desse público. O conceito teórico de Estatística vai ser explorado a partir de atividades do cotidiano dos alunos identificadas via questionário, promovendo uma qualificação em conteúdos que envolvem a Estatística e o desenvolvimento do pensamento estatístico.

\section{REFERÊNCIAS}

BRASIL. Secretaria de Educação Fundamental. Parâmetros Curriculares Nacionais: Matemática. Brasília: MEC/SEF, 1998.

CAZORLA, I. M.; CASTRO, F. C. de. O papel da estatística na leitura do mundo: o letramento estatístico. UEPG Humanit. Sci., Appl. Soc. Sci., Linguist., Lett. Arts, Ponta Grossa, 16 (1) 45-53, jun. 2008.

LOPES, C. E.; COUTINHO, C.Q.; ALMOULOUD, S. Estudos e reflexões em educação estatística. 1. Ed. Campinas: Ed. Mercado de Letras, 2010. 